Research Article

\title{
Trends and Determinants of Fertility in Pakistan: Multivariate Decomposition Analysis (PDHS 1990-91 to PDHS 2012-13)
}

\author{
Asifa Kamal ${ }^{1 *}$, Ghazala Noreen ${ }^{1}$ and Muhammad Amin ${ }^{2}$
}

${ }^{1}$ Lahore College for Women University Lahore, Pakistan; ${ }^{2}$ Nuclear Institute for Food and Agriculture (NIFA), Peshawar, Khyber Pakhtunkhwa, Pakistan.

\begin{abstract}
Pakistan is facing problem of rapid population growth. Objective of current study is to identify the demographic, economic and attitudinal factors affecting fertility in Pakistan for the three waves of cross sectional Pakistan Demographic and Health Surveys (PSHS 1990-91, PDHS 2006-07 and PDHS 201213). Multivariate decomposition analysis and pooled cross section techniques are used to analyse the data. It is concluded from multivariate pooled analysis of three surveys that age of women at first birth, region (Balochistan), wealth index (rich), education of both spouses and survey periods (2006-07, 2012-13) has significantly negative effect on the total children ever born to women in Pakistan. Child mortality (yes), husband's desire for children (more than wife), ideal number of children, marital duration and ever use of contraceptives has significant positive contribution towards women fertility in terms of number of children ever born to women. A significant decline in fertility is observed for the two periods (PDHS 2006-07 and PDHS 2012-13) as compared to PDHS (1990-91). There is 10\% and 15\% decline in fertility in 2006-07 and 2012-13 respectively as compared to 1990-91.

Received | November 17, 2020; Accepted | December 10, 2020; Published | January 26, 2021

*Correspondence | Asifa Kamal, Lahore College for Women University Lahore, Pakistan; Email: asifa.kamal@lcwu.edu.pk, asifa.k53@gmail. com

Citation | Kamal, A., Noreen, G. and Amin, M., 2020. Trends and determinants of fertility in Pakistan: Multivariate decomposition analysis (PDHS 1990-91 to PDHS 2012-13). Journal of Innovative Sciences, 7(1): 6-17.

DOI | http://dx.doi.org/10.17582/journal.jis/2021/7.1.6.17

Keywords | Multivariate decomposition analysis, PDHS, Children ever born, Pooled data analysis, Poisson regression model, Compositional effect, Behavioural effect, Fertility determinants
\end{abstract}

\section{Introduction}

$\mathrm{P}$ opulation of Pakistan is now 6.4 times more as compared to 1951 (NIPSP, 2013). It is claimed that demographic transition in Pakistan has been started. But the pace of that demographic transition is slow that after nineteen years, population of Pakistan reached from 129.1 million in 1989 census to 207.7 million in 2017 census (Pakistan Bureau of Statistics, 2017). From 1981 to 2017, rise in population is 146.6\%.Among most populous countries of the world, Pakistan has reached to the position of $5^{\text {th }}$ in 2017 which was $14^{\text {th }}$ in 1951 (Pakistan Bureau of Statistics, 2017). Average annual growth rate of population is
2.4 which is alarming. Reduction in mortality rate is faster than the birth rates. Life expectancy is also improving with passage of time. It increased to 66.5 and 64.6 years in 2013, for females and males that was 63.4 and 62.4 respectively in 1989 (NIPSP, 2013). All this contributed increase in population of country.

This rapid population growth has adverse effect on standard of living of Pakistani people. Almost 24.3\% of population is living below poverty line (Asian Development Bank, 2020). Food insecurity increased from $58 \%$ to $77 \%$ households from 2005 to 2014 (Hashmi et al., 2018). Children (primary level) not going to school are 9.45 million (Najam and Bari, 
2017). Pakistan is among top ten countries who has not access to safe drinking water and almost half has not access to improved sanitation (Cooper, 2018). Sixty percent of Pakistani population is younger than 30, among those only 39 percent are employed (Najam and Bari, 2017). These indicators showed that efforts in achieving the sustainable development goals will be devastating with this population growth. Rapid increase in population is like a bomb on the development of Pakistan in the presence of scarce resources and slow economic growth.

Reduction in population growth without attaining the replacement level of fertility is not possible. Fertility in Pakistan has started declining after 1990's. Before 1990, the claim of fertility decline is controversial (Nasir et al., 2009). Mean children ever born for all women declined from 3.0 (PDHS 1990-91) to 2.42 (PDHS, 2012-13) but it is still above the replacement level of fertility. After 65 years, desired targets are not achieved and it is forecasted that population of Pakistan could be doubled in 2050 (Constable, 2017).

Fertility levels are the result of fertility preferences and fertility control (Rutayisire et al., 2014). Contraceptive prevalence rate is indicator of fertility control. More than one third of currently married women in Pakistan aged (15-49) are using contraceptives (NIPSP, 2013). Contraceptive prevalence rate is now $40.6 \%$ and unmet need of contraceptives is $19.8 \%$ in mid2017 (PPCP, 2017). Fertility is preference derived in Pakistan which has slowed down the fertility control. Women ideal family size is 4.1 children that shows high fertility intention of Pakistani women. It is almost double to replacement level of fertility (NIPSP, 2013).

Studies have been conducted to model the effect of social, economic, demographic and behavioural factors on fertility using Demographic and Health Survey in Nigeria, Bangladesh, Sierra Leone, Nepal, Botswana and Rwanda (Fagbamigbe and Adebowale, 2014; Haque et al., 2015; Conteh-Khali, 2014; Sharma, 2016; Adhikari, 2010; Fatema et al., 2016; Kabir et al., 2001).

It is fact that Pakistan will not attain the desired fertility decline without regular, major and structural societal changes. Objective of current study is to explore the significant factors contributing towards stopping behaviour of fertility in Pakistan after pooling the three PDHS. Inclusion of potential explanatory factors will explain the contribution of these factors in terms of change in fertility attributable to these factors over time.

\section{Materials and Methods}

In the current study, data is taken from three waves of Pakistan Demographic and Household Surveys (PDHS, 1990-91, 2006-07, 2012-13). Target of the study is ever married women of reproductive age 1549. Sample comprised of 6611, 10023 and 13558 women respectively for PDHS, 1990-91, PDHS, 2006-07 and PDHS, 2012-13.

The dependent variable for current study is number of children ever born to a woman that is used as proxy for the measurement of fertility of individual women. Potential independent variables/ factors selected from PDHS file for current study are demographic/ social factors (Age of women, Age of women at marriage, Marital duration, Child mortality, Region of residence, Place of residence, Head of household, Polygyny, Consanguineous marriages), economic factors (Wealth index, Occupation of women, Occupation of husband, Work status of women) and attitudinal factors (Husband desire for children, Fertility intention, Son preference, Ever use of contraceptives).

For modelling children ever born to women, Multivariate decomposition analysis and pooled cross section techniques are used to analyse the data. Multivariate decomposition analysis was used in demographic research by many researchers to study mortality, contraceptive use and birth interval issues (Winter et al., 2013; Muhoza et al., 2016; Njogu, 1994; Worku et al., 2015; MacQuarrie, 2017).

Multivariate decomposition is proposed for current study as it partitions the change over time into two components (1) due to changing effects and (2) due to changing composition.

Dependent variable in current study is count i.e. number of children ever born to women. Multivariate decomposition of Poisson regression model developed by Powers et al. (2011) is used in the current data, the decomposition of count models is:

$\bar{Y}_{A} / \bar{R}_{A}-\bar{Y}_{B} / \bar{R}_{B}=\overline{F\left(X_{A} \beta_{A}+\log R_{A}\right)} / \bar{R}_{A}-\overline{F\left(X_{B} \beta_{B}+\log R_{B}\right)} / \bar{R}_{B}$ 
Where endowment component is:

$$
E=\overline{F\left(X_{A} \beta_{A}+\log R_{A}\right)} / \bar{R}_{A}-\overline{F\left(X_{B} \beta_{A}+\log R_{B}\right)} / \bar{R}_{B}
$$

And coefficient component is:

$$
C=\overline{F\left(X_{B} \beta_{A}+\log R_{B}\right)} / \bar{R}_{B}-\overline{F\left(X_{B} \beta_{B}+\log R_{B}\right)} / \bar{R}_{B}
$$

Here " $R$ " is number of events divided by the total amount of exposure to risk. Data is analysed using survey setting command in STATA 15.

Pooled cross sections are obtained by collecting random samples from a large population independently of each other at different points in time. It is data structure that is useful to study impact of policy (Wooldridge, 2010). Every method used for pure cross section analysis can be applied to pooled cross sections. In pooled cross sections, year or period (or other time period) is used as dummies to account for aggregate changes over time.

\section{Results and Discussion}

Histogram (Figures 1, 2, 3) showed that response variable i.e. children ever born (CEB) to women is positively skewed. Mean number of children ever born to married women in Pakistan had started declining (Table 1). It can be observed from (Figures 1, 2, 3) that decline in the children ever born to women was more for PDHS (2012-13) as compared to PDHS (2006-07) and PDHS (1990-91).

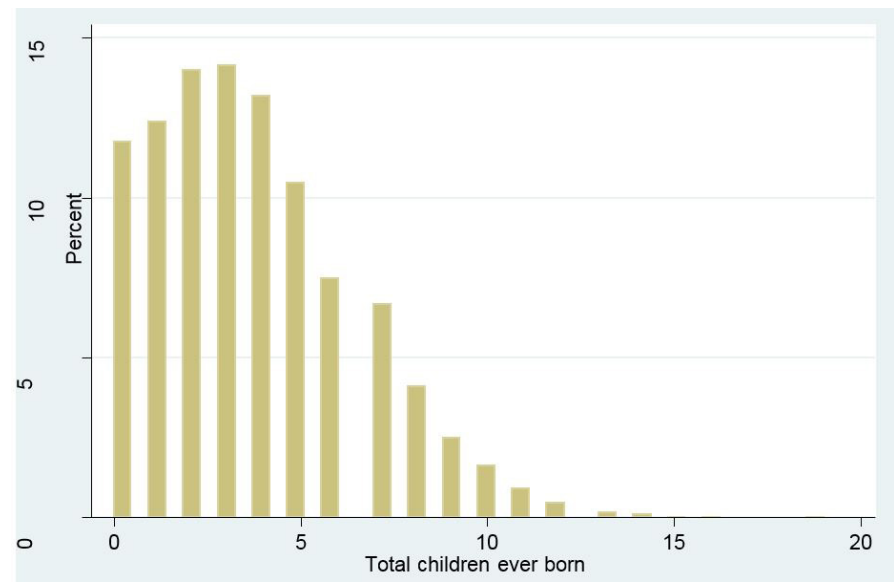

Figure 1: Histogram showing children ever born to women PDHS (2012-13).

\subsection{Trends and differentials in fertility}

Consistent decline in mean children ever born is observed for various categories of women characteristics between the three surveys (Table 2). Difference in mean children ever born is observed positive over time for only poorest women, women engaged in agriculture sector, uneducated women, women who had uneducated husband and women who had intended family size of more than two children for PDHS 1990-91 and PDHS 2006-07. No change is observed in mean children ever born for age of women at first birth (15-24), region (KPK, Balochistan), place of residence (rural) between 1990-91 and 2006-07. Mean children ever born was also similar for women aged 15-24 in the latter two surveys.

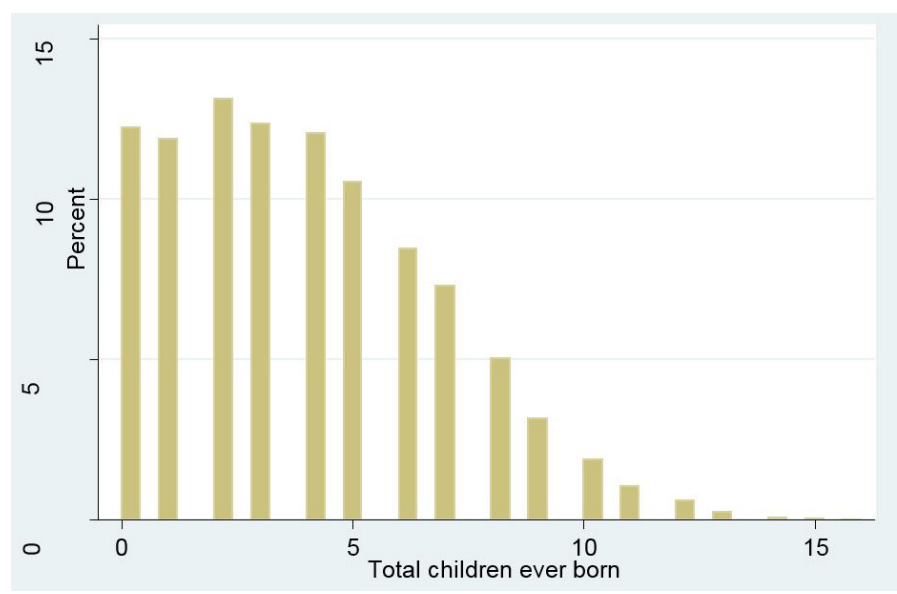

Figure 2: Histogram showing children ever born to women PDHS (2006-07).

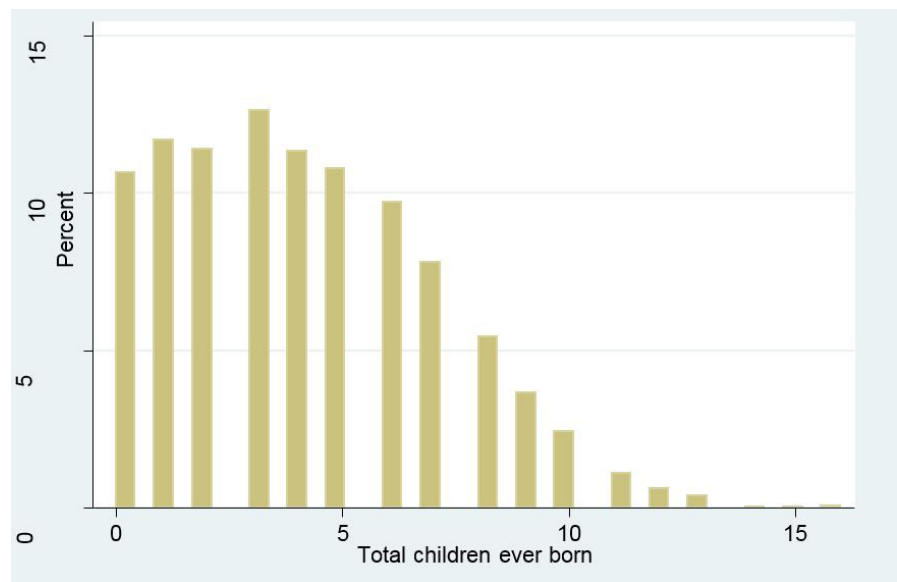

Figure 3: Histogram showing children ever born to women PDHS (1990-91).

Table 1: Summary statistics of CEB (PDHS 199091, 2006-07, 2012-13).

\begin{tabular}{llllll}
\hline Variable & Sample size & Mean & SD & Min & Max \\
\hline PDHS 2012-13 & 13558 & 3.6 & 2.7 & 0 & 10 \\
PDHS 2006-07 & 10023 & 3.9 & 2.9 & 0 & 16 \\
PDHS 1990-91 & 6611 & 4.1 & 2.9 & 0 & 16 \\
\hline
\end{tabular}

Maximum decline in mean children ever born $(-0.7)$ 
for two earlier period surveys is observed for the following characteristics of women i.e. age of women at first birth $(25+)$, husband desire for number of children (same or fewer than wife) and non-users of contraceptives. For later two surveys elevated decline in difference of mean children ever born $(-0.8)$ is found for daughter preference. Unexpectedly more decline in mean children ever born was for non-users of contraceptive as compared to users.

Table 2: Mean children ever born and the difference in mean children ever born between surveys, by selected background characteristics of the women, PDHS 1990-91 to PDHS 2012-13.

\begin{tabular}{lll}
\hline $\begin{array}{l}\text { Categories } \\
\text { of factors }\end{array}$ & $\begin{array}{l}\text { Mean children ever } \\
\text { born ever married } \\
\text { women }\end{array}$ & $\begin{array}{l}\text { Difference in mean } \\
\text { children ever born } \\
\text { between surveys }\end{array}$ \\
\cline { 2 - 3 } & 19912007 2013 Total 2007-1991 2013-2007 \\
\hline
\end{tabular}

Age of women

$\begin{array}{lllllll}15-24 & 1.3 & 1.2 & 1.2 & 1.2 & -0.1 & 0.0 \\ 25-34 & 3.7 & 3.3 & 3.1 & 3.3 & -0.4 & -0.2 \\ 35+ & 6.1 & 5.7 & 5.3 & 5.6 & -0.4 & -0.4\end{array}$

Marital duration

$\begin{array}{lllllll}<20 & 3.2 & 2.9 & 2.7 & 2.9 & -0.3 & -0.2 \\ \geq 20 & 6.7 & 6.3 & 6.0 & 6.3 & -0.4 & -0.3\end{array}$

Age of women at first birth

$\begin{array}{lllllll}<15 & 6.1 & 5.8 & 6.1 & 6.0 & -0.3 & 0.3 \\ 15-24 & 4.6 & 4.6 & 4.3 & 4.5 & 0.0 & -0.3 \\ 25+ & 3.9 & 3.2 & 2.9 & 3.2 & -0.7 & -0.3\end{array}$

Child mortality

$\begin{array}{lllllll}\text { No } & 3.2 & 3.1 & 2.8 & 3.0 & -0.1 & -0.3 \\ \text { Yes } & 6.2 & 6.0 & 5.9 & 6.0 & -0.2 & -0.1\end{array}$

Region

Punjab

$\begin{array}{lllll}4.0 & 3.8 & 3.6 & 3.7 & -0.2\end{array}$

Sindh

$\begin{array}{lllll}4.3 & 3.9 & 3.6 & 3.8 & -0.4\end{array}$

$-0.3$

KPK

$\begin{array}{lllll}4.1 & 4.1 & 3.7 & 4.0 & 0.0\end{array}$

$-0.4$

$\begin{array}{llllll}\text { Balochistan } & 3.8 & 3.8 & 4.1 & 3.9 & 0.0\end{array}$

Place of residence

$\begin{array}{lllllll}\text { Urban } & 4.2 & 3.7 & 3.4 & 3.6 & -0.5 & -0.3 \\ \text { Rural } & 4.0 & 4.0 & 3.7 & 3.9 & 0.0 & -0.3\end{array}$

Cousin marriage

$\begin{array}{lllllll}\text { No } & 4.2 & 3.8 & 3.5 & 3.8 & -0.4 & -0.3 \\ \text { Yes } & 4.0 & 3.9 & 3.7 & 3.8 & -0.1 & -0.2\end{array}$

Wealth index

$\begin{array}{lllllll}\text { Poor } & 4.0 & 4.2 & 4.0 & 4.1 & 0.2 & -0.2 \\ \text { Middle } & 4.2 & 4.1 & 3.8 & 4.0 & -0.1 & -0.3 \\ \text { Rich } & 4.0 & 3.5 & 3.2 & 3.5 & -0.5 & -0.3\end{array}$

Women's occupation

$\begin{array}{llllll}\text { Not working } & 4.0 & 3.7 & 3.5 & 3.7 & -0.3\end{array}$

\begin{tabular}{|c|c|c|c|c|c|c|}
\hline \multirow[t]{2}{*}{$\begin{array}{l}\text { Categories } \\
\text { of factors }\end{array}$} & \multicolumn{4}{|c|}{$\begin{array}{l}\text { Mean children ever } \\
\text { born ever married } \\
\text { women }\end{array}$} & \multicolumn{2}{|c|}{$\begin{array}{l}\text { Difference in mean } \\
\text { children ever born } \\
\text { between surveys }\end{array}$} \\
\hline & 1991 & 2007 & 2013 & Total & $2007-1991$ & $2013-2007$ \\
\hline Manual & 4.5 & 4.2 & 4.0 & 4.1 & -0.3 & -0.2 \\
\hline Agriculture & 4.4 & 4.6 & 4.3 & 4.4 & 0.2 & -0.3 \\
\hline White collar & 3.8 & 3.3 & 3.2 & 3.3 & -0.5 & -0.1 \\
\hline \multicolumn{7}{|c|}{ Women's education } \\
\hline Not educated & 4.3 & 4.4 & 4.3 & 4.3 & 0.1 & -0.1 \\
\hline Educated & 3.3 & 3.0 & 2.7 & 2.9 & -0.3 & -0.3 \\
\hline \multicolumn{7}{|c|}{ Husband's education } \\
\hline Not educated & 4.4 & 4.5 & 4.3 & 4.4 & 0.1 & -0.2 \\
\hline Educated & 3.7 & 3.5 & 3.3 & 3.4 & -0.2 & -0.2 \\
\hline \multicolumn{7}{|c|}{ Husband desire for children } \\
\hline $\begin{array}{l}\text { Same/fewer } \\
\text { than wife }\end{array}$ & 4.1 & 3.4 & 3.2 & 3.5 & -0.7 & -0.2 \\
\hline $\begin{array}{l}\text { More than } \\
\text { wife }\end{array}$ & 4.2 & 4.3 & 4.0 & 4.1 & 0.3 & -0.3 \\
\hline \multicolumn{7}{|c|}{ Fertility intention (Ideal number of children) } \\
\hline$\leq 2$ & 2.8 & 2.5 & 2.2 & 2.4 & -0.3 & -0.3 \\
\hline$>2$ & 3.8 & 4.0 & 3.8 & 3.9 & 0.2 & -0.2 \\
\hline \multicolumn{7}{|c|}{ Gender preference } \\
\hline $\begin{array}{l}\text { No/balanced } \\
\text { preference }\end{array}$ & 3.6 & 3.8 & 3.5 & 3.6 & 0.2 & -0.3 \\
\hline $\begin{array}{l}\text { Daughter } \\
\text { preference }\end{array}$ & 4.1 & 4.6 & 3.8 & 4.2 & 0.5 & -0.8 \\
\hline $\begin{array}{l}\text { Son prefer- } \\
\text { ence }\end{array}$ & 3.7 & 3.9 & 3.8 & 3.9 & 0.2 & -0.1 \\
\hline \multicolumn{7}{|c|}{ Ever use of contraceptives } \\
\hline No & 3.8 & 3.1 & 2.7 & 3.2 & -0.7 & -0.4 \\
\hline Yes & 5.2 & 4.7 & 4.4 & 4.6 & -0.5 & -0.3 \\
\hline
\end{tabular}

Pooled analysis of three cross sectional surveys is reported in Table 3 using Poisson regression model. It can be observed from Table 3 that all factors contributed significantly towards children ever born to women except region (Sindh, KPK), women's place of residence, cousin marriage, women's occupation and gender preference. Age of women at first birth, region (Balochistan), wealth index (rich), education of both spouses and survey periods (2006-07, 2012-13) has significantly negative effect on the total children ever born to women in Pakistan. Child mortality (yes), husband's desire for children (more than wife), ideal number of children, marital duration and ever use of contraceptives has significant positive contribution towards women fertility in terms of number of children ever born to women. A significant decline in fertility is observed for the two periods (PDHS 2006-07 and PDHS 2012-13) as compared to PDHS (1990-91). 
There is $10 \%$ and $15 \%$ decline in fertility in 2006-07 and 2012-13 respectively as compared to 1990-91.

Incidence rate ratio (IRR) of the significant factors is interpreted assuming that all other factors are kept constant. Increase in the age of women is significantly positively related to total number of children ever born. There is $4 \%(I R R=1.04)$ increase in the relative rate of having a child for a woman who was one year older as compared to her counterpart. Increase in age of women at first birth declined her exposure to risk of giving birth. There is almost 5\% (IRR=0.95) decrease in the relative risk of having more births for per year increase in the age of women at first birth. The relative rate of having one more child is increased by $27 \%$ $(I R R=1.27)$ if women had experienced a child death.

Children ever born to woman in the three provinces (Sindh, KPK and Balochistan) were less as compared to Punjabi women. Women living in Balochistan had significantly less number of children as compared to Punjabi women. Relative risk of having less number of children is $4 \%(\mathrm{IRR}=0.96)$ for Balochi women as compared to Punjabi women.

Current study has shown that rural women are more likely to have more children than urban women $(\mathrm{IRR}=1.01)$. Number of children born to consanguineous couples are insignificantly less as compared to their counterparts (IRR=0.99). It is observed that wealth index has inverse relationship with fertility. The relative rate of having a child is 2\% (IRR=0.98) and 9\% (IRR=0.91) less for middle and rich women, respectively as compared to poor women. Effect less number of children (IRR=0.99) as compared to non-working women but effect is insignificant.

The relative rate for having more children is $5 \%$ (IRR=0.95) less for educated women as compared to uneducated women. The relative rate for having more children is $3 \%$ (IRR=0.97) less for women who had educated husband as compared to women who had uneducated husband. There is difference of $2 \%$ in the effect of education in lowering fertility in case of women's education than husband's education. The relative rate of having a child is almost $10 \%$ $(\mathrm{IRR}=1.10)$ more for a woman whose husband desired more children than her. A single increase in a desired (intended) number of children resulted in 5\% (IRR=1.05) increase in the risk of having more actual number of children. Exposure to risk of conception has positive relationship with fertility so effect of all higher categories of marital duration are significantly positive as compared to lowest marital duration (0-4 years).

To get in-depth insight into change in fertility of Pakistan, it is tried to decompose the changes in the fertility using multivariate decomposition analysis (Tables 4, 5 and 6). Change is isolated as change in composition (endowments) of the female population and changes due to shift in their fertility behaviour (coefficients/effects).

Endowments explain compositional effect while coefficients tell about behavioural effect. Compositional effect means change in the distribution of women selected characteristics and the behavioural effect means, size of the effect of women selected characteristics also recognized as "coefficients". Two later period survey (PDHS, 2006-07 and PDHS, 2012-13) comparison shows that combined effect of all changes in characteristics (endowments) would have been to decrease in the fertility by $2.3 \%$ points (a $7.8 \%$ decrease). The combined effect of all coefficients would have been to decrease the fertility by $27.5 \%$ points (a 92.2\% decrease) due to behavioural effect. Alternatively, it can be interpreted as if the composition of the women population had remained the same for 2006-07 and 2012-13, fertility would have been 2.3 percent-points higher. If the behaviour had not changed, fertility would have been 27.5 percent-points higher. The total decline in fertility is approximately by 0.30 points between the 2007 and 2013 surveys. Effect of endowments, coefficients and overall effect is statistically significant for the two periods under study.

Multivariate decomposition analysis for two earlier surveys (1990-91 and 2006-07) has not shown overall decline in fertility. Combined compositional effect (endowments) would have been to significantly increase in the fertility by 0.73 points (a $247.76 \%$ increase). Combined effect of all coefficients is in opposite direction and resulted in significant fertility decline by 0.45 points (a $147.8 \%$ decrease). Positive nature of endowments effect has dampened the coefficients effect of fertility decline.

It can be concluded that decline in fertility due to both endowment (coverage) and behaviour occurred which consequently resulted in overall decline in fertility in the latter two period only. 
Table 3: Poisson regression model of CEB to women with selected socio-economic and behavioural characteristics PDHS 1990-91 to PDHS 2012-13.

\begin{tabular}{|c|c|c|c|c|c|}
\hline CEB & & & & 95\% C.I. & \\
\hline Factors & Categories & IRR & Std. Err. & & \\
\hline Age of women & & $1.043745^{*}$ & .0018561 & 1.04011 & 1.047392 \\
\hline Age of women at first birth & & $.9515184^{*}$ & .0016794 & .9482301 & .9548181 \\
\hline Child mortality & No & & & & \\
\hline & Yes & $1.265572^{*}$ & .0117228 & 1.242786 & 1.288776 \\
\hline Region & Punjab & & & & \\
\hline & Sindh & .9839938 & .0111227 & .962417 & 1.006054 \\
\hline & KPK & .9844221 & .0106792 & .9636964 & 1.005594 \\
\hline & Balochistan & $.9573449^{*}$ & .0193308 & .9201691 & .9960225 \\
\hline Place of residence & Urban & & & & \\
\hline & Rural & 1.013108 & .0108067 & .9921317 & 1.034529 \\
\hline Cousin marriage & No & & & & \\
\hline & Yes & .9885842 & .0076317 & .9737275 & 1.003668 \\
\hline Wealth index & Poor & & & & \\
\hline & Middle & .9841801 & .0107953 & .9632316 & 1.005584 \\
\hline & Rich & $.9118393^{*}$ & .0104116 & .8916441 & .9324918 \\
\hline Women's occupation & No & & & & \\
\hline & Yes & .9992007 & .0080809 & .9834753 & 1.015177 \\
\hline Women's education & No & & & & \\
\hline & Yes & $.9476547^{*}$ & .0091801 & .9298182 & .9658333 \\
\hline Husband's e' ducation & No & & & & \\
\hline & Yes & $.9688135^{*}$ & .0082092 & .9528444 & .9850503 \\
\hline Husband desire for children & Same/Fewer & & & & \\
\hline & More than wife & $1.096263^{*}$ & .0088074 & 1.079123 & 1.113676 \\
\hline Fertility intention & (ideal number of children) & $1.05232^{*}$ & .0026602 & 1.047115 & 1.057551 \\
\hline Gender preference & No/Balanced preference & & & & \\
\hline & Daughter preference & 1.020406 & .0181062 & .985502 & 1.056546 \\
\hline & Son preference & .9871368 & .0084321 & .9707351 & 1.003816 \\
\hline Ever use of contraceptive & No & & & & \\
\hline & Yes & $1.181681^{*}$ & .0098364 & 1.162544 & 1.201133 \\
\hline Marital duration & $0-4$ & & & & \\
\hline & $5-9$ & $1.482685^{*}$ & .0199296 & 1.444104 & 1.522296 \\
\hline & $10-14$ & $1.723625^{*}$ & .031344 & 1.663229 & 1.786216 \\
\hline & $15-19$ & $1.713735^{*}$ & .0450309 & 1.627646 & 1.804378 \\
\hline & $20-24$ & $1.564458^{*}$ & .0523462 & 1.465079 & 1.670578 \\
\hline & $25-29$ & $1.388452^{*}$ & .0596424 & 1.276258 & 1.510509 \\
\hline & $30+$ & $1.267313^{*}$ & .0649828 & 1.146051 & 1.401406 \\
\hline Survey & $2006-07$ & $.898421^{*}$ & .0130331 & .8732172 & .9243523 \\
\hline & $2012-13$ & $.8536335^{*}$ & .0124876 & .8294874 & .8784825 \\
\hline _cons & & $1.421817^{*}$ & .0459844 & 1.334421 & 1.514936 \\
\hline
\end{tabular}

*significant at 5\% level of significance.

Table 4: Difference due to endowments and coefficients (PDHS, 1990-91; 2006-07; 2012-13). PDHS 2012-13 and PDHS 2006-07

\begin{tabular}{llllll}
\hline CEB & Coef. & P>z & 95\% Conf. interval & Pct. \\
\hline E=Difference due to endowments & -.023239 & 0.000 & -.032599 & -.013879 & 7.7934 \\
C=Difference due to coefficients & -.27495 & 0.000 & -.3255 & -.22441 & 92.207 \\
R=Total difference & -.29819 & 0.000 & -.34921 & -.24717 & \\
PDHS 2006-07 and PDHS 1990-91 & & & & & \\
E=Difference due to endowments & .75234 & 0.000 & .7259 & .77878 & 247.76 \\
C=Difference due to coefficients & -.44869 & 0.000 & -.48309 & -.41428 & -147.76 \\
R=Total Difference & .30365 & 0.000 & .25561 & .3517 & \\
\hline
\end{tabular}

Journal of Innovative Sciences

June 2021 | Volume 7| Issue 1 | Page 11 
Table 5: Multivariate decomposition of women selected characteristics difference in CEB, showing contribution to CEB gap attributed to difference in endowments and to difference in coefficients, PDHS 2006-7 and PDHS 2012-13.

\begin{tabular}{|c|c|c|c|c|c|}
\hline \multirow{2}{*}{$\begin{array}{l}\text { CEB } \\
\text { Factors }\end{array}$} & \multicolumn{5}{|c|}{ PDHS 2012-13 and PDHS 2006-07 } \\
\hline & Categories & Endow. & Pct. & Coeff. & Pct. \\
\hline Age of Women & & $-.015272^{*}$ & 5.1215 & $-.61015^{*}$ & 204.61 \\
\hline Age of Women at first birth & & $.0017256^{*}$ & -.57867 & .23304 & -78.15 \\
\hline \multirow[t]{3}{*}{ Child Mortality } & No & $.0011106^{*}$ & -.37244 & $-.057851^{*}$ & 19.4 \\
\hline & Yes & $-.0016634^{*}$ & .55784 & $.023842^{*}$ & -7.9956 \\
\hline & S/Total & -0.00055 & 0.1854 & -0.03401 & 11.4044 \\
\hline \multirow[t]{5}{*}{ Region } & Punjab & -.0001712 & .057412 & -.0050255 & 1.6853 \\
\hline & Sindh & .00022108 & -.07414 & $-.035484^{*}$ & 11.9 \\
\hline & KPK & -.000024745 & .008298 & $-.023065^{*}$ & 7.7348 \\
\hline & Balochistan & -.000025847 & .008668 & $.014018^{*}$ & -4.7009 \\
\hline & S/Total & $-7.12 \mathrm{E}-07$ & 0.000238 & -0.00503 & 16.6192 \\
\hline \multirow[t]{3}{*}{ Place of residence } & Urban & $6.1221 \mathrm{e}-06$ & .002053 & .016692 & -5.5978 \\
\hline & Rural & $-3.4548 \mathrm{e}-06$ & .001159 & -.031794 & 10.662 \\
\hline & S/Total & $2.67 \mathrm{E}-06$ & 0.003212 & -0.0151 & 5.0642 \\
\hline \multirow[t]{3}{*}{ Cousin Marriage } & No & $.00019532^{*}$ & -.0655 & $.030045^{*}$ & -10.076 \\
\hline & Yes & $.00061631^{*}$ & -.20668 & $-.060218^{*}$ & 20.194 \\
\hline & S/Total & 0.000812 & -0.27218 & -0.030173 & 10.118 \\
\hline \multirow[t]{4}{*}{ Wealth Index } & Poor & $-.0004527^{*}$ & .15182 & -.021778 & 7.3033 \\
\hline & Middle & $.000091609^{*}$ & -.030721 & .0016671 & -.55907 \\
\hline & Rich & $.00066451^{*}$ & -.22285 & .019408 & -6.5084 \\
\hline & S/Total & 0.000303419 & -0.101751 & -0.0007 & 0.23583 \\
\hline \multirow[t]{3}{*}{ Women's Occupation } & No & -.000019739 & .00662 & -.017468 & 5.8578 \\
\hline & Yes & -.00023473 & .078719 & .0077666 & -2.6045 \\
\hline & S/Total & -0.00025 & 0.085339 & -0.0097014 & 3.2533 \\
\hline \multirow[t]{3}{*}{ Women's Education } & No & $-.0040495^{*}$ & 1.358 & .0099086 & -3.3229 \\
\hline & Yes & $-.0032561^{*}$ & 1.0919 & -.0052219 & 1.7512 \\
\hline & S/Total & -0.00731 & 2.4499 & 0.0046867 & -1.5717 \\
\hline \multirow[t]{3}{*}{ Husband's Education } & No & $-.00055807^{*}$ & .18715 & .015059 & -5.0502 \\
\hline & Yes & $-.00021089^{*}$ & .070724 & -.027149 & 9.1046 \\
\hline & S/Total & -0.000769 & 0.257874 & -0.01209 & 4.0544 \\
\hline \multirow[t]{3}{*}{ Husband desire for children } & Same/Fewer & $-.0012325^{*}$ & .41331 & -.022101 & 7.4115 \\
\hline & More than wife & $.0030798^{*}$ & -1.0328 & .0079642 & -2.6708 \\
\hline & S/Total & 0.0018473 & -0.61949 & -0.0141368 & 4.7407 \\
\hline Fertility intention & (ideal number of children) & $-.0053965^{*}$ & 1.8097 & .11231 & -37.663 \\
\hline \multirow[t]{4}{*}{ Gender Preference } & No/Balanced preference & -.00057498 & .19282 & -.020705 & 6.9434 \\
\hline & Daughter preference & -.00037684 & .12637 & .00068653 & -.23023 \\
\hline & Son preference & .0017876 & -.59947 & .0071547 & -2.3994 \\
\hline & S/Total & 0.00083578 & -0.28028 & -0.01286 & 4.31377 \\
\hline \multirow[t]{3}{*}{ Ever Use of Contraceptive } & No & $.010652^{*}$ & -3.5722 & $-.033483^{*}$ & 11.229 \\
\hline & Yes & $.0081792^{*}$ & -2.7429 & $.040677^{*}$ & -13.641 \\
\hline & S/Total & 0.0188312 & -6.3151 & 0.007194 & -2.412 \\
\hline cons & & & & .1563 & -52.415 \\
\hline
\end{tabular}

*significant at $5 \%$ level of significance. 
In the Table 5 the endowment columns measure the amount of increase/decrease in fertility explained by the change in composition in each of factors between the two time periods, assuming that the effect of the factor was constant across the entire period. The coefficient column measures the amount of increase/decrease in fertility explained by the change in effect (coefficients) between the two time points, if composition had been constant across the entire period. Decrease in fertility between 2006-07 and 2012-13 is higher due to change in the behavioural effect. Factors that contributed significantly towards decline in fertility between the two periods are age of women (5.12\%) and women's education (2.45\%). These factors contributed the highest share in explaining the fertility gap from endowments. Without this change, fertility in 2012-13 would have been 1.5 percent-points and 0.73 percentpoints high. Other factors that contributed significantly in declining the fertility in terms of endowments are child mortality (yes), wealth index (poor), husband's education and fertility intention.

After controlling for compositional effect, the coefficient effect becomes more pronounced. The intercept term (cons) shows that there is an overall shift to higher fertility in 2012-13 if compared to how women behaved in 2006-07. Keeping other factors constant, significant decline in fertility between the two periods due to behavioural change is higher for age of women, child mortality (no), region (Sindh, KPK), cousin marriage (yes) and ever use of contraceptives (no) when endowments effect is held constant.

Share of ever user of contraceptive in reducing fertility is lower in 2012-13 as compared to non-users. This proportion has not caused decline in fertility 201213. On the other hand, non-users shared their contribution in declining the fertility.

Table 6 of multivariate decomposition model displays parameter estimates for categories that contribute positively or negatively towards shift in fertility between the two periods PDHS 1990-91 and PDHS 2006-07. Decrease in fertility between 1990-91 and 2006-07 is lower due to change in the behavioural effect. Factors that contributed significantly towards decline in fertility between the two periods due to endowments when behaviours are assumed to be constant are age of women at first birth (57.741\%), Balochistan region $(2.1311 \%)$ and son preference
$(0.37747 \%)$. These factors contributed the highest share in explaining the decline in fertility from endowments. Without this change, fertility in 200607 would have been $17.53 \%, 0.64 \%$ percent-points and $0.11 \%$ percent-points high due to women age at first birth, region (Balochistan) and son preference respectively. Share of increase in population of women for indicators like child mortality (yes), region (Sindh, $\mathrm{KPK}$ ), wealth index, educated women, high fertility intention and ever user/non users of contraceptive has increased contribution towards higher fertility (endowments effect of indicators).

The intercept term shows that there is an overall shift to higher fertility in 2006-07 if compared to how women behaved in 1990-91. Keeping endowments effect constant, significant decline in fertility between the two periods due to behavioural effect is only for age of women and nonworking women.

Maximum decline in mean children ever born for two earlier period surveys is observed for the following characteristics of women i.e. age of women at first birth $(25+)$, husband desire for number of children (same or fewer than wife) and non-users of contraceptives. For later two surveys elevated decline in difference of mean children ever born is found for daughter preference. Unexpectedly more decline in mean children ever born is for non-users of contraceptive as compared to users. A significant decline in fertility is observed for the two periods (PDHS 2006-07 and PDHS 201213) as compared to PDHS (1990-91). There is $10 \%$ and 15\% decline in fertility in 2006-07 and 2012-13 respectively as compared to 1990-91. Biological factor age of women has positive association with number of children ever born. On contrary, age of women at first birth has inverse relationship with number of children ever born to women. Both of these factors are in line with the universal findings reported in earlier studies. Effect of mortality is observed positive on fertility due to wish of child replacement or child hoarding concept. Pakistan has agro based economy and in rural areas more number of children are preferred to help parents in farming. Reason of high fertility in rural setting may also be attributable to less contraceptive prevalence. Effect of consanguineous marriages is not strong on fertility in current study. Fertility of couple is found less in case of consanguineous marriages (Kamal and Pervaiz, 2011). Reason might be risk of child mortality in cousin marriage due to possibility of transfer of hereditary or genetic diseases. 
Table 6: Multivariate decomposition of women selected characteristics difference in CEB, showing contribution to $\mathrm{CEB}$ gap attributed to difference in endowments and to difference in coefficients, PDHS 1990-91 and PDHS 2006-07.

\begin{tabular}{|c|c|c|c|c|c|}
\hline \multicolumn{2}{|l|}{ CEB } & \multicolumn{4}{|c|}{ PDHS 2006-07 and PDHS 1990-91 } \\
\hline Factors & Categories & Endow. & Pct. & Coeff. & Pct. \\
\hline Age of women & & $.53054^{*}$ & 174.72 & $-.54854^{*}$ & -180.65 \\
\hline Age of Women at first birth & & $-.17533^{*}$ & -57.741 & -.40473 & -133.29 \\
\hline \multirow[t]{3}{*}{ Child Mortality } & No & $-.0020976^{*}$ & -.69079 & .077609 & 25.558 \\
\hline & Yes & $.011443^{*}$ & 3.7686 & -.029489 & -9.7113 \\
\hline & S/Total & 0.0093454 & 3.07781 & 0.04812 & 15.8467 \\
\hline \multirow[t]{5}{*}{ Region } & Punjab & -.0027939 & -.92008 & .0028328 & .9329 \\
\hline & Sindh & $.0022033^{*}$ & .72561 & -.026891 & -8.8558 \\
\hline & KPK & $.0026176^{*}$ & .86204 & -.010744 & -3.5381 \\
\hline & Balochistan & $-.0064712^{*}$ & -2.1311 & .0033267 & 1.0956 \\
\hline & S/Total & -0.0044442 & -1.46353 & -0.03148 & -10.3654 \\
\hline \multirow[t]{3}{*}{ Place of residence } & Urban & .0051401 & 1.6927 & -.033569 & -11.055 \\
\hline & Rural & .0065095 & 2.1437 & .038385 & 12.641 \\
\hline & S/Total & 0.0116496 & 3.8364 & 0.004816 & 1.586 \\
\hline \multirow[t]{3}{*}{ Cousin Marriage } & No & .000040092 & .013203 & .0086028 & 2.8331 \\
\hline & Yes & .000057175 & .018829 & -.012034 & -3.963 \\
\hline & S/Total & $9.727 \mathrm{E}-05$ & 0.032032 & -0.0034312 & -1.1299 \\
\hline \multirow[t]{4}{*}{ Wealth Index } & Poor & $.028273^{*}$ & 9.311 & .0019947 & .65691 \\
\hline & Middle & $.0031999^{*}$ & 1.0538 & -.0030663 & -1.0098 \\
\hline & Rich & $.043011^{*}$ & 14.165 & .0069752 & 2.2971 \\
\hline & S/Total & 0.0744839 & 24.5298 & 0.005904 & 1.94421 \\
\hline \multirow[t]{3}{*}{ Women's Occupation } & No & .0026569 & .87497 & $-.1366^{*}$ & -44.986 \\
\hline & Yes & .0032217 & 1.061 & $.023006^{*}$ & 7.5764 \\
\hline & S/Total & 0.0058786 & 1.93597 & -0.113594 & -37.4096 \\
\hline \multirow[t]{3}{*}{ Women's Education } & No & $.0046794^{*}$ & 1.541 & -.016334 & -5.3791 \\
\hline & Yes & $.00058321^{*}$ & .19207 & .0091747 & 3.0214 \\
\hline & S/Total & 0.0052626 & 1.73307 & -0.0071593 & -2.3577 \\
\hline \multirow[t]{3}{*}{ Husband's Education } & No & .000076446 & .025175 & .0055334 & 1.8223 \\
\hline & Yes & -.00086326 & -.28429 & -.0096272 & -3.1705 \\
\hline & S/Total & -0.000787 & -0.259115 & -0.0040938 & -1.3482 \\
\hline \multirow[t]{3}{*}{ Husband desire for children } & Same/Fewer & $.018643^{*}$ & 6.1397 & -.049781 & -16.394 \\
\hline & More than wife & $.0083955^{*}$ & 2.7648 & .01207 & 3.9749 \\
\hline & S/Total & 0.0270385 & 8.9045 & -0.037711 & -12.4191 \\
\hline Fertility intention & (ideal number of children) & $.045208^{*}$ & 14.888 & .19279 & 63.489 \\
\hline \multirow[t]{4}{*}{ Gender Preference } & No/Balanced preference & .000096994 & .031942 & -.019681 & -6.4813 \\
\hline & Daughter preference & -.0003038 & -.10005 & .004199 & 1.3828 \\
\hline & Son preference & $-.0011462^{*}$ & -.37747 & -.025835 & -8.5081 \\
\hline & S/Total & -0.001353006 & -0.44558 & -0.04132 & -13.6066 \\
\hline \multirow[t]{3}{*}{ Ever Use of Contraceptive } & No & $.057226^{*}$ & 18.846 & .02434 & 8.0157 \\
\hline & Yes & $.069262^{*}$ & 22.81 & -.015769 & -5.1932 \\
\hline & S/Total & 0.126488 & 41.656 & 0.008571 & 2.8225 \\
\hline _cons & & & & .48317 & 159.12 \\
\hline
\end{tabular}

*significant at $5 \%$ level of significance. 
Theory of opportunity cost is not working strongly in lowering fertility in the context of Pakistan. Effect of women work status on fertility depends on reward from work, education and access to family planning methods which is not up to the level of developed countries. Hashmi and Zafar (1997) concluded same but Hakim (1994) found inconsistent negative association between women's work and fertility. Sathar et al. (1988) concluded that women's participation in labour market is not associated with increase in her income or status so effect is not strong as observed in developed countries.

Education of both spouses has significant negative relationship with children ever born to women. Contribution of women's education towards fertility is more than husband's education. Education effect fertility by delaying marriages, contraceptive awareness and labour force participation of women. Women whose husband wanted more children than her had significantly more children as compared to women whose husband wanted same of fewer children than her. Hashmi and Zafar (1997) had also found same trend. Pakistan is patriarchal society and there is strong male dominance. This behaviour influences all household decisions. Husband's desire for more children prevent women from using family planning methods.

In Pakistan fertility is preference driven and women desired number of children is high as compared to Government's targeted replacement level of fertility. Positive relationship is found in current study between actual and intended fertility. Effect of son preference is not strongly related with fertility. Nature of relationship is also doubtful which require further investigations.

Women who used contraceptives had significantly higher number of children as compared to nonuser women. High fecundity of users group may be responsible for this association (Kamal and Pervaiz, 2012). Maximum percentage of women had used contraceptives after fifth children (Kamal and Pervaiz, 2011). Pakistan Social and Living Standards Measurement Survey (2006-07) indicated that 35\% of women had used contraceptives when they had more than 5 children. It means prevalence rate is higher among women with high parity. Couples are using contraceptive for spacing and not for stopping the child bearing (Kamal and Pervaiz, 2012).
It is evident from multivariate decomposition model that positive nature of endowments effect has dampened the coefficient effect of fertility decline in earlier two surveys (PDHS 1990-91 and PDHS 2006-07). For the latter two surveys (PDHS 2006-07 and PDHS 2012-13), fertility declined significantly due to both compositional and behavioural change. Contribution of behavioural change in declining fertility is more as compared to change in sample population or compositional change. Overall change in the composition of women population for factors like age of women, child mortality, women's occupation, women's education, husband's education and fertility intention contributed negatively towards fertility. Compositional change of age of women at first birth, cousin marriage, wealth index, husband desire for children, ever use of contraceptives and fertility intention has strong contribution towards increase in fertility.

It is interesting to note that change in proportion of women whose husband wanted fewer children has negative contribution on fertility but this decline is cancelled out by positive impact towards fertility for those women whose husbands wanted more children than her.

Behavioural change towards decreasing fertility is significant for age of women, no child mortality, region (Sindh, KPK), consanguineous marriages, and non-users of contraceptives. Predominant contribution towards decreasing fertility is due to effect of behavioural change for factor age of women. Child mortality (no) and cousin marriage (yes) has positive contribution towards compositional change in fertility but its behavioural effect is negative.

\section{Conclusions and Recommendations}

It is concluded that age of women at first birth, region (Balochistan), wealth index (rich), education of both spouses and survey periods (2006-07, 2012-13) has significantly negative effect on the total children ever born to women in Pakistan. Child mortality (yes), husband's desire for children (more than wife), ideal number of children, marital duration and ever use of contraceptives has significant positive contribution towards women fertility in terms of number of children ever born to women. A significant decline in fertility is observed for the two periods (PDHS 2006-07 and PDHS 2012-13) as compared to PDHS 
(1990-91). There is $10 \%$ and $15 \%$ decline in fertility in 2006-07 and 2012-13 respectively as compared to 1990-91. For the latter two surveys (PDHS 2006-07 and PDHS 2012-13), fertility declined significantly due to both compositional and behavioural change. Contribution of behavioural change in declining fertility is more as compared to change compositional change in later two surveys.

It is recommended to policy makers in family planning program to pay more focus in launching programs to transform attitude of both Pakistani men and women towards small family. Uneducated couples should be particularly concentrated in these campaigns.

\section{Novelty Statement}

Current article addressed the major problem of Pakistan. Trends and determinants of fertility in Pakistan has been explored using MVDCMP model, covering almost 20 years span.

\section{Author's Contribution}

Asifa Kamal: Research idea and estimation of models, result section.

Ghazala Noreen: Write up of paper, final review. Muhammad Amin: Estimation of models and result section.

\section{Conflict of interest}

The authors have declared no conflict of interest.

\section{References}

Adhikari, R., 2010. Demographic, socioeconomic, and cultural factors affecting fertility differentials in Nepal. $B M C$ pregnancy and childbirth, 10(1): 19. http://www.biomedcentral. com/1471-2393/10/19

Asian Development Bank. 2020. Poverty data: Pakistan. Accessed on 12, December, 2020 https://www.adb.org/countries/pakistan/ poverty

Constable, P., 2017. A disaster in the making: Pakistan's population surges to 207.7 million. The Washington Post. Retrieved from https://www. thespec.com/news-story/7546100--a-disasterin-the-making-pakistan-s-population-surgesto-207-7-million/. Accessed 08 march, 2018.
Conteh-Khali, N., 2014. Socioeconomic and Cultural Factors Influencing Desired Family Size in Sierra Leone. Bowling Green State University. https:// etd.ohiolink.edu/pg_10?0::NO:10:P10_ ACCESSION_NUM:bgsu1403713225

Cooper, R., 2018. Water, sanitation and hygiene services in Pakistan. https://assets.publishing. service.gov.uk/media/5c6c2b4be5274a72be398f0a/502_Water__Sanitation_and_Hygiene_in_Pakistan.pdf

Fagbamigbe, A.F. and Adebowale, A.S., 2014. Current and predicted fertility using Poisson regression model: evidence from 2008 Nigerian demographic health survey. African Journal of Reproductive Health, 18(1): 71-83.

Fatema T.J., Lata, S.P. and Noorunnahar. 2016. Factors influencing higher child birth and population growth in Bangladesh. International Journal of Scientific Research and Management Human, 4(4): 308-322.

Hakim, A., 1994. Factors affecting fertility in Pakistan. Pakistan Development Review, 33(4 Pt 2): 685-706.

Haque, A., Hossain, T. and Nasser, M., 2015. Predicting the number of children ever born using logistic regression model. Biometrics and Biostatistics International Journal, 2(4): 00034.

Hashmi, A.A., Sial, M.H., Akram, W. and Hashmi, M.H., 2018. Assessing food insecurity trends and determinants by using mix methods in Pakistan: Evidence from household pooled data (2005-2014). Sarhad Journal of Agriculture, 35(1): 87-101.

Hashmi, N., and Zafar, M.I., 1997. Determinants of marital fertility in Pakistan. Pakistan Journal Agriculture Science, 4: 58-61.

Kabir, A., Barbhuiya, M. and Islam, M.S., 2001. Determinants of fertility in Bangladesh: Evidence from the three national surveys. The Sciences, 1(5): 302-307.

Kamal, A. and Pervaiz, M.K., 2011. Factors affecting the family size in Pakistan: Cloglog Regression model analysis. Journal of Statistics, 18: 29-53.

Kamal, A. and Pervaiz, M.K., 2012. Determinants of higher order birth intervals in Pakistan. Journal of Statistics, 19: 54-82.

MacQuarrie, K.L.D., 2017. The association of marriage age with fertility timing in Asia. Population association of America annual meetings Chicago, IL, April 27-29, 2017. 
file://C:/Users/Dr.\%20Asifa/Downloads/ MacQuarrie\%20hz\%20decomp\%20PAA\%20 abstract.pdf

Muhoza, D.N., Rutayisire, P.C. and Umubyeyi, A., 2016. Measuring the success of family planning initiatives in Rwanda: A multivariate decomposition analysis. Journal of Population Research, 33(4): 361-377.

Najam, A. and Bari, F., 2017. Pakistan national buman development report. Unleashing the potential of a Young Pakistan. Islamabad: UNDP.

Nasir,J.A., Akhtar, M. and Tahir, M.H., 2009. Reproductivity and age-specific fertility rates in Pakistan after 1981. Pakistan Journal of Statistics, 25(3): 251-263.

National Institute of Population Studies, Pakistan, 2013. Family Planning, Pakistan Demographic and Health Survey 2012-13.Islamabad,Pakistan: National Institute of Population Studies Islamabad, Pakistan and Macro International Inc. Calverton, Maryland, USA.

Njogu, W., 1994. A decade of change in contraceptive behaviour in Latin America: a multivariate decomposition analysis. Population Bulletin of the United Nations, 36: 81-109.

Pakistan Bureau of Statistics, 2017. Provisional summary results of $6^{\text {th }}$ Population and Housing Census 2017. Retrieved from http://www.pbs. gov.pk/content/provsional-summary-results6th-population-and-housing-census-2017-0. Accessed 08 march, 2018.

Population Planning Commission of Pakistan, 2017. Population, Track 20 Project (FP 2020). Chapter 3. Islamabad: Pakistan. http://pc.gov.
pk/uploads/annual2017/Ch03-Population.pdf. Accessed 08 march, 2018.

Powers, D.A., Yoshioka, H. and Yun, M.S., 2011. Mvdcmp: Multivariate decomposition for nonlinear response models. Stata Journal, 11(4): 556-576. https://doi. org/10.1177/1536867X1101100404

Rutayisire, P.C., Hooimeijer, P. and Broekhuis, A., 2014. Change in fertility decline in Rwanda: A decomposition analysis. International Journal of Population Research, Article ID 486210. https:// doi.org/10.1155/2014/486210

Sathar, Z., 1988. Birth spacing in Pakistan. Journal of Biosocial Science, 20(2): 175-194. https://doi. org/10.1017/S0021932000017417

Sharma, M.P., 2016. The determinants of fertility among women of reproductive age in Nepal. Journal of Development and Administrative Studies, $\quad 23(1-2): \quad 55-68 . \quad$ https://doi. org/10.3126/jodas.v23i1-2.15448

Winter, R., Pullum, T., Langston, A., Mivumbi, N., Rutayisire, P., Muhoza, D. and Hakiba, S., 2013. Trends in neonatal mortality in Rwanda 2000-2010. Further analysis of the Rwanda Demographic and Health Surveys.

Wooldridge, J.M., 2010. Econometric analysis of cross section and panel data. MIT press.

Worku, A.G., Tessema, G.A. and Zeleke, A.A., 2015. Trends of modern contraceptive use among young married women based on the 2000, 2005, and 2011 Ethiopian demographic and health surveys: A multivariate decomposition analysis. PLoS One, 10(1): e0116525. https:// doi.org/10.1371/journal.pone.0116525 